\title{
SNM Practice Guideline for Brain Death Scintigraphy 2.0
}

\author{
Kevin J. Donohoe ${ }^{1}$ (Chair), Garima Agrawal ${ }^{2}$, Kirk A. Frey ${ }^{3}$, Victor H. Gerbaudo ${ }^{4}$, Giuliano Mariani ${ }^{5}$, James S. Nagel ${ }^{6}$, \\ Barry L. Shulkin ${ }^{7}$, Michael G. Stabin ${ }^{8}$, and Margaret K. Stokes ${ }^{1}$ \\ ${ }^{1}$ Beth Israel Deaconess Medical Center, Boston, Massachusetts; ${ }^{2}$ Mallinckrodt Institute of Radiology, St. Louis, Missouri, ${ }^{3}$ University \\ of Michigan Medical Center, Ann Arbor, Michigan; ${ }^{4}$ Brigham and Women's Hospital, Boston, Massachusetts; ${ }^{5}$ University of Pisa \\ Medical School, Pisa, Italy; ${ }^{6}$ VA Boston Healthcare System, West Roxbury, Massachusetts; ${ }^{7}$ St. Jude Children's Research Hospital, \\ Memphis, Tennessee; and ${ }^{8}$ Vanderbilt University, Nashville, Tennessee
}

\section{PREAMBLE}

The Society of Nuclear Medicine (SNM) is an international scientific and professional organization founded in 1954 to promote the science, technology, and practical application of nuclear medicine. Its 16,000 members are physicians, technologists, and scientists specializing in the research and practice of nuclear medicine. In addition to publishing journals, newsletters, and books, the SNM also sponsors international meetings and workshops designed to increase the competencies of nuclear medicine practitioners and to promote new advances in the science of nuclear medicine.

The SNM will periodically define new guidelines for nuclear medicine practice to help advance the science of nuclear medicine and to improve the quality of service to patients throughout the United States. Existing practice guidelines will be reviewed for revision or renewal, as appropriate, on their fifth anniversary or sooner, if indicated.

Each practice guideline, representing a policy statement by the SNM, has undergone a thorough consensus process in which it has been subjected to extensive review, requiring the approval of the Committee on Guidelines and SNM Board of Directors. The SNM recognizes that the safe and effective use of diagnostic nuclear medicine imaging requires specific training, skills, and techniques, as described in each document. Reproduction or modification of the published practice guideline by those entities not providing these services is not authorized.

These guidelines are an educational tool designed to assist practitioners in providing appropriate care for patients. They are not inflexible rules or requirements of practice and are not intended, nor should they be used, to establish a legal standard of care. For these reasons and those set forth below, the SNM cautions against the use of these guidelines in litigation in which the clinical decisions of a practitioner are called into question.

Received Feb. 27, 2012; accepted Feb. 27, 2012.

For correspondence or reprints contact: Kevin Donohoe, Beth Israel Deaconess Medical Center, 330 Brookline Ave., Boston, MA 02215.

E-mail: kdonohoe@caregroup.harvard.edu

Published online Jun. 28, 2012.

COPYRIGHT (C) 2012 by the Society of Nuclear Medicine and Molecular Imaging, Inc.

DOI: $10.2967 /$ jnmt.112.105130
The ultimate judgment regarding the propriety of any specific procedure or course of action must be made by the physician or medical physicist in light of all the circumstances presented. Thus, there is no implication that an approach differing from the guidelines, standing alone, is below the standard of care. To the contrary, a conscientious practitioner may responsibly adopt a course of action different from that set forth in the guidelines when, in the reasonable judgment of the practitioner, such course of action is indicated by the condition of the patient, limitations of available resources, or advances in knowledge or technology subsequent to publication of the guidelines.

The practice of medicine includes both the art and the science of the prevention, diagnosis, alleviation, and treatment of disease. The variety and complexity of human conditions make it impossible to always reach the most appropriate diagnosis or to predict with certainty a particular response to treatment. Therefore, it should be recognized that adherence to these guidelines will not ensure an accurate diagnosis or a successful outcome. All that should be expected is that the practitioner will follow a reasonable course of action based on current knowledge, available resources, and the needs of the patient to deliver effective and safe medical care. The sole purpose of these guidelines is to assist practitioners in achieving this objective.

\section{INTRODUCTION}

The purpose of this guideline is to assist nuclear medicine practitioners in recommending, performing, interpreting, and reporting the results of brain perfusion imaging to assist in confirming the diagnosis of brain death.

\section{GOALS}

The goal of this guideline is to describe some of the elements common to optimal performance of brain death scintigraphy.

\section{DEFINITIONS}

See also the SNM Guideline for General Imaging.

The diagnosis of brain death is a clinical diagnosis that is sometimes confirmed with cerebral perfusion scintigraphy $(1,2)$. It is important that all physicians be knowledgeable about the clinical requirements for the diagnosis of brain 
death, especially the need to establish irreversible cessation of all function of the cerebrum and brain stem (3). Institutions performing scintigraphy for the evaluation of possible brain death should develop clinical guidelines and procedures for the clinical diagnosis that incorporate both clinical evaluations and ancillary tests such as perfusion scintigraphy (4).

\section{COMMON CLINICAL INDICATIONS}

Brain death scintigraphy is indicated for the assessment of brain blood flow in patients suspected of brain death (5-12). This study may be helpful when clinical assessment and electroencephalography are less reliable in diagnosing brain death because of conditions such as severe hypothermia, coma caused by barbiturates, electrolyte or acid-base imbalance, endocrine disturbances, drug intoxication, poisoning, and neuromuscular blockade. Brain death scintigraphy may also be helpful in patients who are being considered as possible organ donors (7) or when family members require documentation of lack of blood flow.

\section{QUALIFICATIONS AND RESPONSIBILITES OF PERSONNEL (IN THE UNITED STATES)}

Refer to the SNM Guideline for General Imaging.

\section{PROCEDURE/SPECIFICATIONS OF THE EXAMINATION}

\section{A. Patient preparation}

The patient should have a stable blood pressure, and all correctable major systemic biochemical abnormalities should be addressed. Patients may be unstable, making transportation and SPECT logistically difficult and hazardous for the patient. Before the patient is moved, the relative risks and benefits of imaging away from the patient's room, such as with SPECT or SPECT/CT, should be weighed.

In some institutions a tourniquet is placed, encircling the head just above the eyebrows, ears, and around the posterior prominence of the skull. The tourniquet can help diminish scalp blood flow, preventing it from being confused with brain blood flow. However, a tourniquet should not be used in patients with a history of head trauma when there is a concern that the tourniquet will exacerbate the injury. Patients should be normally ventilated to prevent changes in cerebral blood flow that may be caused by hyperventilation.

\section{B. Information pertinent to performing the procedure}

A history of head trauma or central nervous system injury should be obtained. Trauma or focal central nervous system ischemia or infection may cause abnormalities in blood flow that may complicate image interpretation. Clinical findings should also be reviewed, such as the results of neurologic tests and any other testing that may support the diagnosis of brain death. Additional brain imaging studies should be reviewed, if available.

It should be determined if the patient can be positioned as needed for brain perfusion imaging. Anterior or posterior images should be properly aligned so that symmetry of blood flow to both sides of the head and superior sagittal sinus activity can be assessed. Care should be taken to note if the patient has recently received barbiturates. At high levels, these agents may decrease cerebral blood flow (13).

\section{Precautions}

No precautions are required.

\section{Radiopharmaceutical}

See also the SNM Guideline for Use of Radiopharmaceuticals.

Several ${ }^{99 \mathrm{~m}}$ Tc-labeled agents may be used $(6,14,15)$, including ${ }^{99 \mathrm{~m} T c-b i c i s a t e ~(E C D ; ~ e t h y l ~ c y s t e i n a t e ~ d i m e r), ~}$ 99m Tc-exametazime (HMPAO; hexamethylpropylene amine oxime), and ${ }^{99 m}$ Tc-pentetate (DTPA; diethylenetriaminepentaacetic acid). Although brain-specific tracers such as ${ }^{99 \mathrm{~m}} \mathrm{Tc}-\mathrm{HMPAO}$ and ${ }^{99 \mathrm{~m}} \mathrm{Tc}-\mathrm{ECD}$ are increasing in popularity, there is no clear evidence that they are more accurate than nonspecific agents. Brain-specific agents are preferred by some institutions because their interpretation is far less dependent on the quality of the bolus and because delayed images are usually definitive for the presence or absence of cerebral blood flow. Brain-specific agents also offer the advantage of allowing evaluation of regional brain tissue perfusion and hence brain via-

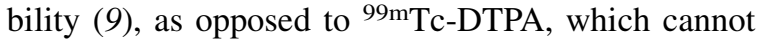
cross the blood-brain barrier and therefore provides information only on low-resolution vascular flow.

In adults, up to $1,110 \mathrm{MBq}(30 \mathrm{mCi})$ of administered activity may be used. Administered activity for children should be determined on the basis of body weight and should be as low as reasonably achievable for diagnostic image quality. The typical dose in children is $11.1 \mathrm{MBq} / \mathrm{kg}(0.3 \mathrm{mCi} / \mathrm{kg})$, and the minimum dose is $185 \mathrm{MBq}(5 \mathrm{mCi})$ for brain-specific agents.

The Brain Imaging Council of the SNM feels that although individual laboratories may have used and may continue to use agents such as ${ }^{99 \mathrm{~m}} \mathrm{Tc}-\mathrm{DTPA}$, glucoheptonate, and pertechnetate, these are less commonly used than $99 \mathrm{~m}$ Tc-HMPAO and ${ }^{99 \mathrm{~m}} \mathrm{Tc}-$ ECD for assessment of cerebral perfusion (16).

\section{E. Image acquisition}

Flow images should be acquired. They are essential for interpretation of studies using non-brain-binding agents such as ${ }^{99 m}$ Tc-DTPA. In studies using brainspecific agents, such as ${ }^{99 \mathrm{~m}} \mathrm{Tc}-\mathrm{HMPAO}$ and ${ }^{99 \mathrm{~m} T \mathrm{Tc}-}$ ECD, poor (or suboptimal) visualization of the brain on delayed images could conceivably be caused by improper preparation or instability of the radiopharma- 
ceutical. Flow images will help to confirm lack of brain blood flow when the brain is not visualized on delayed images using ${ }^{99 \mathrm{~m} T c-H M P A O}$ and ${ }^{99 m}$ Tc-ECD. Flow images are acquired at the time of tracer injection. A 15\%-20\% energy window centered around 140 $\mathrm{keV}$ is set before the start of imaging, and the images are obtained at $1 \mathrm{~s}$ per frame for at least $60 \mathrm{~s}$. If better spatial resolution is required, 1-s frames can be combined into 2 or $3 \mathrm{~s}$ per frame. The acquisition should start before or at the time of injection, to ensure imaging begins before the bolus reaches the carotid arteries and ends well after the venous phase.

If a non-brain-binding agent such as ${ }^{99 \mathrm{~m}}$ Tc-DTPA is used, static planar images are acquired in anterior (and posterior, if helpful) and 1 lateral view for 500,000 to $1,000,000$ counts per view. Zooming or magnification may be helpful, particularly in pediatric cases. For brain-specific agents, images should be obtained after approximately $20 \mathrm{~min}$. Planar images should be obtained in anterior, right lateral, left lateral, and (if possible) posterior projections if SPECT is not feasible (17).

When brain-specific agents such as ${ }^{99 \mathrm{~m} T c-H M P A O}$ and ${ }^{99 \mathrm{~m}}$ Tc-ECD are used, SPECT images may be obtained in addition to flow and planar images. SPECT allows better visualization of perfusion to the posterior fossa and brain stem structures (16); however, SPECT acquisition is often not feasible with unstable patients on life support equipment. Multiple-detector or other dedicated SPECT cameras generally produce results superior to single-detector general-purpose units. However, with meticulous attention to procedure, highquality images can be produced on single-detector units with appropriately longer scan times $\left(5 \times 10^{6}\right.$ total counts or more are desirable). The smallest radius of rotation possible with appropriate patient safeguards should be used (11), and high-resolution or ultra-highresolution collimation is recommended (11). Low-energy high-resolution or ultra-high-resolution collimators may be used. Fan-beam or other focused collimators are preferable to parallel-hole collimators because the former provide improved resolution and higher counting rates. However, care must be taken to ensure that the entire brain is visualized in all projections to avoid the problem of incomplete views. When parallel-hole collimation is used, care should be taken to ensure that adequate counts are obtained. A $128 \times 128$ or greater acquisition matrix is preferred, and the camera zoom should be set to produce a pixel size of $3.5 \mathrm{~mm}$ or less.

Continuous acquisition may provide a shorter total scan duration than does a step-and-shoot technique. When continuous acquisition is used, it is important that angular sampling of $3^{\circ}$ or less be used. The acquisition pixel size should be one third to one half the expected reconstructed resolution. It may be neces- sary to use a hardware zoom to achieve an appropriate pixel size. Different zoom factors may be used with the in-plane and axial dimensions of a fan-beam collimator. The time per stop and number of counts acquired for the study will depend on the amount of tracer activity in the brain and the specific camera being used. It is suggested that the number of seconds per stop be similar to that used on the facility's equipment for acquiring other brain SPECT studies. It is frequently useful to apply detector pan and zoom capabilities to ensure that the entire brain is included in the field of view while allowing the detector to clear the shoulders. Segmentation of data acquisition into multiple sequential acquisitions will permit exclusion of bad data-for example, removal of segments of projection data that include patient motion. The scan may also be repeated if there is excessive patient motion.

\section{F. Interventions}

No interventions are required.

\section{G. Processing of SPECT}

Studies should be filtered in 3 dimensions either by 2-dimensionally prefiltering the projection data or by applying a 3-dimensional postprocessing filter to the reconstructed data. Low-pass (e.g., Butterworth) filters should be used. Resolution recovery or spatial variation of the filters should be used with caution, however, as they may produce artifacts. The entire brain should always be reconstructed, with care taken not to exclude the cerebellum or vertex (17). Data should be reconstructed at the highest pixel resolution, that is, 1 pixel thick. If slices are to be summed, the summing should be done only after reconstruction and oblique reorientation (if performed).

\section{H. Interpretation criteria}

The President's Council on Brain Death (1982) determined that of the 4 examinations available to establish the presence or absence of brain death, 2 (clinical examination and properly performed 4-vessel cerebral angiography) are diagnostic and 2 (electroencephalography and cerebral scintigraphy) are confirmatory. Thus, one may confirm but not diagnose brain death with cerebral scintigraphy. According to evidence-based review, radionuclide studies remain an acceptable corroborative test (12).

A technically adequate study is mandatory for interpretation. The absence of demonstrable radionuclide activity within the brain is consistent with the diagnosis of brain death but is not in itself sufficient to allow this diagnosis and should be correlated with other findings. Images viewed on a computer screen rather than on film or paper copy permit interactive adjustment of contrast, background subtraction, and color table. 
TABLE 1

Radiation Dosimetry: Adults $(24,25)$

\begin{tabular}{|c|c|c|c|c|c|c|c|}
\hline \multirow[b]{2}{*}{ Radiopharmaceutical } & \multicolumn{2}{|c|}{$\begin{array}{l}\text { Administered activity } \\
\text { (intravenous) }\end{array}$} & \multicolumn{3}{|c|}{ Largest radiation dose } & \multicolumn{2}{|c|}{ Effective dose } \\
\hline & $\mathrm{MBq}$ & $\mathrm{mCi}$ & Organ & mGy/MBq & $\mathrm{rad} / \mathrm{mCi}$ & $\overline{\mathrm{mSv}} / \mathrm{MBq}$ & $\mathrm{rem} / \mathrm{mCi}$ \\
\hline 99mTc-DTPA (24) & $555-1,110$ & $15-30$ & Bladder wall & 0.065 & 0.24 & 0.0063 & 0.023 \\
\hline 99mTc-HMPAO (25) & $370-1,110$ & $10-30$ & Kidneys & 0.034 & 0.0126 & 0.0093 & 0.034 \\
\hline 99mTc-ECD & $370-1,110$ & $10-30$ & Bladder wall & 0.05 & 0.18 & 0.0077 & 0.028 \\
\hline
\end{tabular}

1. Studies using brain-specific agents

Flow images are assessed for blood flow to the brain. Anterior views are preferred for imaging blood flow; the head should be viewed straight on to allow for comparison of right and left carotid flow. Tracer flow should be observed from the level of the carotids to the skull vertex. In the anterior position, the right and left middle cerebral arteries course from the midline to the lateral aspects of the skull. The anterior cerebral arteries appear midline and appear as a single vessel.

In brain death, intracranial blood is completely absent. There may be an accompanying blush of activity apparently in the region of the nose on anterior views ("hot nose" sign), which is more likely to represent rerouted blood flow to the region of the brain stem or cervical region of the spinal cord (18). Care must be taken to distinguish external carotid circulation to the scalp from internal carotid circulation to the brain (19).

The superior sagittal sinus is often noted during the venous phase of blood flow in patients with intact blood flow to the brain. However, low-level sagittal sinus activity can come from the scalp. If no internal carotid flow or central nervous system perfusion is seen on the flow study, and sagittal sinus activity is minimal, these findings should be noted and a note of caution regarding the accuracy of the interpretation included in the report (20). In cases of head trauma, hyperemic blood flow to injured scalp structures may mimic brain blood flow or superior sagittal sinus activity (5).

Cerebrospinal fluid shunts and intracranial pressure transducers can cause hyperemia resulting in increased scalp flow, possibly causing a falsenegative flow study. Disruptions in the skull and scalp, as well as pressure on the portion of the scalp resting on a hard surface, can produce a relatively photopenic area on the flow study, falsely suggesting diminished flow.

In order for the diagnosis of brain death to be made in studies using brain-specific agents, delayed planar or SPECT images should demonstrate no tracer uptake in the brain. For SPECT studies, un- processed projection images should be reviewed in cinematic display before viewing of tomographic sections. Projection data should be assessed for target-to-background ratio and other potential artifacts. Inspection of the projection data in sinogram form may also be useful. Both cerebral hemispheres and the posterior fossa (cerebellum) should be evaluated for a complete study. Therefore, the use of planar scintigraphy commonly requires an anteroposterior or posteroanterior view separating left and right hemispheres and at least 1 lateral view to distinguish the cerebral flow from the cerebellar flow $(9,14,21)$.

Gray scale is preferred to color tables. At very low levels of activity, color tables usually designed for viewing near-normal activity may underrepresent low activity, causing a false-positive study.

2. Studies using non-brain-binding agents

Delayed images using agents that are not brain specific may show superior sagittal sinus activity even in the presence of brain death in as many as $50 \%$ of patients (20). Lack of superior sagittal sinus activity, however, helps confirm the lack of cerebral perfusion.

\section{DOCUMENTATION/REPORTING}

See also the SNM Guideline for General Imaging.

Reports should include the tracer used, injected activity, and basic imaging information such as whether flow, planar, or SPECT images were obtained. Reports should also describe the extent and severity of brain perfusion deficits. A brief history and description of clinical findings that support the diagnosis of brain death should be included.

If brain-specific agents are used, specific mention of perfusion to the posterior fossa and brain stem may be reported. Because this study is used in combination with other tests and physical examination findings, the final impression of a positive study should state that the study "shows no evidence of brain perfusion" rather than "demonstrates brain death." When the study shows intracerebral perfusion, state "brain perfusion is present." Severely decreased brain perfusion is often progressive. If there is a small amount of remaining perfusion, consider recommending a repeat study $(15,22)$. 
TABLE 2

Radiation Dosimetry: Children (5 Years Old; Normal Renal Function) $(24,25)$

\begin{tabular}{|c|c|c|c|c|c|c|c|c|c|c|c|}
\hline \multirow[b]{2}{*}{ Radiopharmaceutical } & \multicolumn{2}{|c|}{$\begin{array}{l}\text { Administered } \\
\text { activity } \\
\text { (intravenous) }\end{array}$} & \multicolumn{2}{|c|}{$\begin{array}{l}\text { Minimum } \\
\text { dose }\end{array}$} & \multicolumn{2}{|c|}{$\begin{array}{l}\text { Maximum } \\
\text { dose }\end{array}$} & \multicolumn{3}{|c|}{ Largest radiation dose } & \multicolumn{2}{|c|}{ Effective dose } \\
\hline & $\mathrm{MBq} / \mathrm{kg}$ & $\mathrm{mCi} / \mathrm{kg}$ & $\mathrm{MBq}$ & $\mathrm{mCi}$ & $\mathrm{MBq}$ & $\mathrm{mCi}$ & Organ & mGy/MBq & $\mathrm{rad} / \mathrm{mCi}$ & $\mathrm{mSv} / \mathrm{MBq}$ & $\mathrm{rem} / \mathrm{mCi}$ \\
\hline 99mTc-DTPA (24) & 7.4 & 0.2 & 370 & 10 & 740 & 20 & Bladder wall & 0.17 & 0.63 & 0.017 & 0.063 \\
\hline 99mTc-HMPAO (25) & 11.1 & 0.3 & 185 & 5 & 740 & 20 & Thyroid & 0.14 & 0.52 & 0.027 & 0.099 \\
\hline 99mTc-ECD (26) & 11.1 & 0.3 & 185 & 5 & 740 & 20 & Bladder wall & 0.11 & 0.41 & 0.022 & 0.081 \\
\hline
\end{tabular}

\section{EQUIPMENT SPECIFICATION}

\section{A. Instrumentation}

Instrumentation includes a $\gamma$-camera with a field of view large enough to image the entire head and neck (a small-field-of-view portable camera with a diverging collimator to include the entire head and neck in the image may also be used). The collimator should be low-energy high-resolution or ultra-highresolution.

For SPECT, a multiple-detector instrument or a dedicated brain imaging system is preferred to a single-head $\gamma$-camera system. A SPECT/CT camera may also be used, if available.

\section{QUALITY CONTROL AND IMPROVEMENT}

A. See the SNM Guideline for General Imaging.

B. Quality Control

If brain-specific agents are used, high radiochemical purity and stability of the radiopharmaceutical are essential to prevent false-positive results. Substandard radiochemical purity, such as that due to improper preparation or instability, results in a reduced concentration of tracer in the brain. This finding could be falsely interpreted as lack of cerebral perfusion. Intravenous access must be definitely established so that the flow bolus is compact. Infiltration of the injected dose or a prolonged bolus makes evaluation of the flow phase difficult.

\section{Sources of error}

Substandard radiochemical purity of brainspecific radiopharmaceuticals or injection of the wrong radiopharmaceutical can result in falsepositive studies. In addition, tracer can accumulate in the superior sagittal sinus from several sources, and the superior sagittal sinus activity may be mistaken as a sign of cerebral arterial flow (20). Hyperemic scalp structures may result in falsenegative flow studies if nonspecific brain agents are used. Infiltration of tracer at the injection site may cause a false-positive study if the entire dose is infiltrated and not available to the vascular space; absence of activity in the carotid vessels on flow images suggests complete infiltration of the dose. Retained radioactivity from a previous study using ${ }^{99 \mathrm{~m}} \mathrm{Tc}-\mathrm{HMPAO}$ or ${ }^{99 \mathrm{~m}} \mathrm{Tc}-\mathrm{ECD}$ may impede a correct diagnosis for a repeat study on the same day $(15,23)$.

D. Issues requiring further clarification

The relative accuracies of brain-specific and nonspecific agents require further clarification. Also requiring clarification is the clinical necessity of SPECT, the influence of open fontanels in small children on the accuracy of flow studies, and the value of brain-specific agents for the detection of small areas of brain perfusion, such as in the posterior fossa. Whether this increased sensitivity for small areas of residual perfusion will change the ultimate prognosis requires clarification.

\section{RADIATION SAFETY IN IMAGING}

See also the SNM Guideline for General Imaging.

Tables 1-4 present radiation dosimetry data for adults, for children, and for ${ }^{99 \mathrm{~m}} \mathrm{Tc}-\mathrm{DTPA}$ and ${ }^{99 \mathrm{~m}} \mathrm{Tc}-\mathrm{HMPAO}$ in the fetus (no fetal dosimetry is available presently for 99mTc-ECD). Regarding the breast-feeding patient, ICRP publication 106, appendix D, suggests that no interruption of breastfeeding is needed for administration of ${ }^{99 \mathrm{~m} T c-}$ DTPA, ${ }^{99 \mathrm{~m} T c-H M P A O}$, or ${ }^{99 \mathrm{~m} T c-E C D ~(24-27) . ~}$

TABLE 3

99mTc-DTPA in the Pregnant or Potentially Pregnant Patient (27)

\begin{tabular}{llccc}
\hline \multirow{2}{*}{$\begin{array}{c}\text { Stage of } \\
\text { gestation }\end{array}$} & \multicolumn{4}{c}{ Fetal dose } \\
\cline { 2 - 5 } & $\mathrm{mGy} / \mathrm{MBq}$ & $\mathrm{rad} / \mathrm{mCi}$ & $\mathrm{mGy}$ & $\mathrm{rad}$ \\
\hline Early & 0.012 & 0.044 & $6.7-8.9$ & $0.67-0.89$ \\
$3 \mathrm{mo}$ & 0.0087 & 0.032 & $4.8-6.4$ & $0.48-0.64$ \\
$6 \mathrm{mo}$ & 0.0041 & 0.015 & $2.3-3.0$ & $0.23-0.30$ \\
$9 \mathrm{mo}$ & 0.0047 & 0.017 & $2.6-3.5$ & $0.26-0.35$
\end{tabular}

Dose estimates to fetus were provided by Russell et al. (27). Information about possible placental crossover of this compound was included in the calculations. 
TABLE 4

99mTc-HMPAO in the Pregnant or Potentially Pregnant Patient (27)

\begin{tabular}{lcccc}
\hline \multirow{2}{*}{$\begin{array}{c}\text { Stage of } \\
\text { gestation }\end{array}$} & \multicolumn{4}{c}{ Fetal dose } \\
\cline { 2 - 5 } & $\mathrm{mGy} / \mathrm{MBq}$ & $\mathrm{rad} / \mathrm{mCi}$ & $\mathrm{mGy}$ & $\mathrm{rad}$ \\
\hline Early & 0.0087 & 0.032 & $3.2-9.7$ & $0.32-0.97$ \\
$3 \mathrm{mo}$ & 0.0067 & 0.025 & $2.5-7.4$ & $0.25-0.74$ \\
$6 \mathrm{mo}$ & 0.0048 & 0.018 & $1.8-5.3$ & $0.18-0.53$ \\
$9 \mathrm{mo}$ & 0.0036 & 0.013 & $1.3-4.0$ & $0.13-0.40$
\end{tabular}

Dose estimates to fetus were provided by Russell et al. (27). No information about possible placental crossover of this compound was available.

\section{ACKNOWLEDGMENTS}

The Committee on SNM Guidelines consists of the following individuals: Kevin J. Donohoe, MD (Chair) (Beth Israel Deaconess Medical Center, Boston, MA); Sue Abreu, MD (Sue Abreu Consulting, Nichols Hills, OK); Helena Balon, MD (Beaumont Health System, Royal Oak, MI); Twyla Bartel, DO (UAMS, Little Rock, AR); Paul E. Christian, CNMT, BS, PET (Huntsman Cancer Institute, University of Utah, Salt Lake City, UT); Dominique Delbeke, MD (Vanderbilt University Medical Center, Nashville, TN); Vasken Dilsizian, MD (University of Maryland Medical Center, Baltimore, MD); Kent Friedman, MD (NYU School of Medicine, New York, NY); James R. Galt, PhD (Emory University Hospital, Atlanta, GA); Jay A. Harolds, MD (OUHSC-Department of Radiological Science, Edmond, OK); Aaron Jessop, MD (UT MD Anderson Cancer Center, Houston, TX); David H. Lewis, MD (Harborview Medical Center, Seattle, WA); J. Anthony Parker, MD, PhD (Beth Israel Deaconess Medical Center, Boston, MA); James A. Ponto, RPh, BCNP (University of Iowa, Iowa City, IA); Henry Royal, MD (Mallinckrodt Institute of Radiology, St. Louis, MO); Rebecca A. Sajdak, CNMT, FSNMTS (Loyola University Medical Center, Maywood, IL); Heiko Schoder, MD (Memorial Sloan-Kettering Cancer Center, New York, NY); Barry L. Shulkin, MD, MBA (St. Jude Children's Research Hospital, Memphis, TN); Michael G. Stabin, PhD (Vanderbilt University, Nashville, TN); and Mark Tulchinsky, MD (Milton S. Hershey Med Center, Hershey, PA).

\section{REFERENCES}

1. Flowers WM Jr, Patel BR. Accuracy of clinical evaluation in the determination of brain death. South Med J. 2000;93:203-206.

2. Heran MK, Heran NS, Shemie SD. A review of ancillary tests in evaluating brain death. Can J Neurol Sci. 2008;35:409-419.
3. Hoch DB. Brain death: a diagnostic dilemma. J Nucl Med. 1992;33:2211-2213.

4. Haupt WF, Rudolf J. European brain death codes: a comparison of national guidelines. J Neurol. 1999;246:432-437.

5. Al-Shammri S, Al-Feeli M. Confirmation of brain death using brain radionuclide perfusion imaging technique. Med Princ Pract. 2004;13:267-272.

6. Conrad GR, Sinha P. Scintigraphy as a confirmatory test of brain death. Semin Nucl Med. 2003;33:312-323.

7. Harding JW, Chatterton BE. Outcomes of patients referred for confirmation of brain death by ${ }^{99 \mathrm{~m}}$ Tc-exametazime scintigraphy. Intensive Care Med. 2003;29: 539-543.

8. Lu G, Shih WJ, Ryo UY. Findings on Tc-99m HMPAO brain imaging in brain death. Clin Nucl Med. 1996;21:891-893.

9. Munari M, Zucchetta P, Carollo C, et al. Confirmatory tests in the diagnosis of brain death: comparison between SPECT and contrast angiography. Crit Care Med. 2005;33:2068-2073.

10. Okuyaz C, Gucuyener K, Karabacak NI, et al. Tc-99m-HMPAO SPECT in the diagnosis of brain death in children. Pediatr Int. 2004;46:711-714.

11. Spieth M, Abella E, Sutter C, et al. Importance of the lateral view in the evaluation of suspected brain death. Clin Nucl Med. 1995;20:965-968.

12. Wijdicks EF, Varelas PN, Gronseth GS, et al. Evidence-based guideline update: determining brain death in adults: report of the Quality Standards Subcommittee of the American Academy of Neurology. Neurology. 2010;74:1911-1918.

13. López-Navidad A, Caballero F, Domingo P, et al. Early diagnosis of brain death in patients treated with central nervous system depressant drugs. Transplantation. 2000;70:131-135.

14. Bertagna F, Barozzi O, Puta E, et al. Residual brain viability, evaluated by ${ }^{99 \mathrm{~m}} \mathrm{Tc}-$ ECD SPECT in patients with suspected brain death and with confounding clinical factors. Nucl Med Commun. 2009;30:815-821.

15. Larar GN, Nagel JS. Tc-99m HMPAO cerebral perfusion scintigraphy: considerations for timely brain death declaration. J Nucl Med. 1992;33:2209-2211.

16. Bonetti MG, Ciritella P, Valle G, et al. 99m-Tc HM-PAO brain perfusion SPECT in brain death. Neuroradiology. 1995;37:365-369.

17. Devous MD. SPECT functional brain imaging: technical considerations. J Neuroimaging. 1995;5(suppl 1):S2-S13.

18. Appelt EA, Song WS, Phillips WT, et al. The "hot nose" sign on brain death scintigraphy: where does the flow really go? Clin Nucl Med. 2008;33:55-57.

19. Mrhac L, Zakko S, Parikh Y. Brain death: the evaluation of semi-quantitative parameters and other signs in HMPAO scintigraphy. Nucl Med Commun. 1995; 16:1016-1020

20. Lee VW, Hauck RM, Morrison MC, et al. Scintigraphic evaluation of brain death: significance of sagittal sinus visualization. J Nucl Med. 1987;28:12791283.

21. Zuckier LS, Kolano J. Radionuclide studies in the determination of brain death: criteria, concepts, and controversies. Semin Nucl Med. 2008;38:262-273.

22. Facco E, Zucchetta P, Munari M, et al. 99m Tc-HMPAO SPECT in the diagnosis of brain death. Intensive Care Med. 1998;24:911-917.

23. MacDonald A, Burrell S. Infrequently performed studies in nuclear medicine: part 2. J Nucl Med Technol. 2009;37:1-13.

24. International Commission on Radiological Protection. Radiation Dose to Patients from Radiopharmaceuticals. New York, NY: Pergamon Press; 1988. ICRP publication 53.

25. Radiation dose to patients from radiopharmaceuticals (addendum 2 to ICRP publication 53). Ann ICRP. 1998;28:1-126.

26. Radiation dose to patients from radiopharmaceuticals. Addendum 3 to ICRP Publication 53. ICRP Publication 106. Approved by the Commission in October 2007. Ann ICRP. 2008;38:1-197.

27. Russell JR, Stabin MG, Sparks RB, Watson EE. Radiation absorbed dose to the embryo/fetus from radiopharmaceuticals. Health Phys. 1997;73:756-769.

\section{APPROVAL}

This practice guideline (version 2.0) was approved by the Board of Directors of the SNM on June 8, 2012. Version 1.0 was approved on January 25, 2003. 